\title{
Surgery for Recurrent Uterine Cancer Surgical Outcomes and Implications for Survival-A Case Series
}

\author{
Lavinia Domenici, MD, * Katherine Nixon, MD, $+\neq$ Flavia Sorbi, MD, \& Maria Kyrgiou, PhD, MD, $\dagger *$ \\ Joseph Yazbek, MD, PhD, †+ Marcia Hall, MD,// Jeremy Campbell, MD, PhD, I Norma Gibbons, MD,\# \\ Won-Ho Edward Park, MD, † Hani Gabra, MD, PhD, †+ and Christina Fotopoulou, MD, PhD +
}

\begin{abstract}
Objective: The purpose of this study was to describe the patterns of relapse in uterine cancer (UC) and the role of surgery in the recurrent setting.

Methods: We describe surgical and clinical outcomes of all patients who underwent surgery for recurrent UC in a gynecological oncology tertiary referral center between May 1, 2013, and April 30, 2016. Progression-free survival and overall survival were estimated using Kaplan-Meier methods with the surgery at relapse being the starting point.

Results: We evaluated 15 patients with a median age of 66 years. The predominant histology was the endometrioid variant $(\mathrm{n}=11 ; 73.3 \%)$. The median interval between the end of previous treatment and relapse surgery was 24 months (range, $8-164)$. Locoregional pelvic recurrences were the most common type of recurrence $(n=13 ; 86.7 \%)$ with the para-aortic lymph node space being the most commonly affected extrapelvic site $(13 \%)$. Patients predominantly presented with a multifocal pattern of relapse $(\mathrm{n}=10 ; 66.7 \%)$ requiring multivisceral resections such as bowel $(\mathrm{n}=7 ; 46.6 \%)$ and/or bladder/ureteric resections $(\mathrm{n}=8 ; 53.3 \%)$ to achieve complete tumor clearance. All patients were operated tumor free with a 30-day major morbidity and mortality rate of $6.7 \%$ and $0 \%$, respectively. Five patients $(33.3 \%)$ received postoperative chemotherapy or radiotherapy. Five patients (33.3\%) relapsed, and 3 died within a mean follow-up of 12.4 months ( $95 \%$ confidence interval [CI], 6.5-18.2). Two of those patients had a sarcoma. Mean progression-free survival and overall survival for the entire cohort postrelapse surgery was 21.7 months $(95 \% \mathrm{CI}, 13.9-29.5)$ and 26.0 months $(95 \% \mathrm{CI}, 18.4-33.7)$, respectively. Survival was significantly worse in patients with nonendometrioid histology $(P<0.0001)$. Conclusions: Surgery for UC relapse seems feasible with acceptable morbidity and high complete resection rates despite the multifocal patterns of relapse in a selected group of patients in a reference center for gynecological cancers. Larger scale studies are warranted to establish the value of surgery at relapse for UC.
\end{abstract}

Key Words: Uterine cancer, Surgery, Relapse

Received December 9, 2016, and in revised form January 2, 2017.

Accepted for publication January 2, 2017.

(Int J Gynecol Cancer 2017;00: 00-00)

*Department of Gynecology-Obstetrics and Urology, Sapienza University of Rome, Rome, Italy; †West London Gynaecological Cancer Centre, Imperial College Healthcare NHS Trust; \$Ovarian Cancer Action Research Centre, Department of Surgery and Cancer, Imperial College London, London, United Kingdom; §Division of Obstetrics and Gynecology, Department of Biomedical, Clinical and Experimental

Copyright (C) 2017 by IGCS and ESGO

ISSN: $1048-891 \mathrm{X}$

DOI: $10.1097 /$ IGC.0000000000000936
Sciences, University of Florence, Florence, Italy; ||Mount Vernon Cancer Centre, London, United Kingdom; qDepartment of Anaesthetics, Hammersmith Hospital, Imperial College Healthcare NHS Trust; and \#Department of Urology, Charing Cross Hospital, Imperial College Healthcare NHS Trust, London, United Kingdom.

Address correspondence and reprint requests to Christina Fotopoulou, $\mathrm{MD}, \mathrm{PhD}$, Ovarian Cancer Action Research Centre, Department of Surgery and Cancer, Imperial College London, Du Cane Rd, London W12 0NN, United Kingdom. E-mail: chfotopoulou@gmail.com. The authors declare no conflicts of interest. 
U terine cancer (UC) is the fourth most common cancer in Europe for women, with around 9022 new cases diagnosed in 2013 in the United Kingdom. ${ }^{1}$ The UC tends to have a generally good overall prognosis, because more than $70 \%$ of the cases will have a favorable histology and will present at an early stage. ${ }^{2}$ Surgery is considered the gold standard approach at initial diagnosis. Radiation and/or chemotherapy may follow surgery as adjuvant treatment in the presence of adverse risk factors (eg, positive lymph nodes (LN) status, lymphovascular space invasion (LVSI), and advanced stage) or can be the primary treatment choice in more advanced and metastatic disease. ${ }^{2-5}$

Recurrent disease represents more aggressive tumor biology and prognosis, depending on the site and type of relapse, locoregional or distant. In particular, distant metastases in the liver and lung represent the most frequent causes of death in these patients. ${ }^{2,3}$ Relapses are commonly treated with radiotherapy and/or chemotherapy but over the past years, there has been a rising trend toward a cytoreductive surgical approach in highly selected patients, potentially consolidated with adjuvant chemotherapy or radiotherapy, after the paradigm of management of ovarian cancer relapse. ${ }^{6-8}$ However, surgical morbidity needs to be carefully balanced against survival benefit, and at present, the overall experience of this approach is limited. We present here the surgical and clinical outcome of surgery after $\mathrm{UC}$ relapse in a large tertiary referral center over a period of 3 years.

\section{MATERIALS AND METHODS}

Between May 2013 and April 2016, all consecutive patients undergoing surgery because of UC relapse in the West London Gynecological Cancer Centre (Imperial College Healthcare NHS Trust, London) were identified, and data were collected from the institutional tumor registry database after local institutional board approval. Histopathological, surgical, and clinical data were retrieved from the medical records and the tumor registry retrospectively.

Inclusion criteria were patients' good performance status less than 2, seemingly resectable disease as assessed by a specialized multidisciplinary team (MDT), and patient willing to undergo further surgery after informed consent. The exclusion criteria were poor performance status of 2 or more, serious comorbidities that would significantly increase surgical risk, multifocal unresectable disease, and presence of distant unresectable metastases, that is chest, bones, and brain. We did not set any limitations to number or type of previous treatments.

Diagnosis of recurrence was made at routine follow-up on clinical examination and subsequent imaging (computed tomography, magnetic resonance imaging, and ultrasound), with most recurrences being asymptomatic.

All patients with pelvic or abdominal recurrence underwent surgery via laparotomy combined with vaginal approach if necessary. In cases of solitary exophytic vaginal recurrence, these were resected vaginally. We did not have in our center the possibility to perform intraoperative radiation therapy so it was not considered as an option.

Indication for surgery was defined as apparently resectable disease within an MDT setting based on patterns of relapse, previous treatments, patients' comorbidities, symptoms, and preferences. Patients with multifocal unresectable distant metastases in organ parenchyma, large amounts of ascites, or pleural effusions were not considered for surgery.

Adjuvant postoperative treatment depended on the amount of residual disease, the intraoperative findings, the histological subtype, as well as the previous lines and type of treatment.

TABLE 1. Characteristics of patients with recurrent UC selected for surgery

\begin{tabular}{|c|c|}
\hline Variables & Total \\
\hline Age, median (range), y & $66(33-83)$ \\
\hline Body mass index, median (range), $\mathrm{kg} / \mathrm{m}^{2}$ & $27.7(24.8-37.5)$ \\
\hline \multicolumn{2}{|l|}{ Ethnicity, n (\%) } \\
\hline White & $8(53.3)$ \\
\hline Black & $2(13.3)$ \\
\hline Asian/Indian & $5(33.4)$ \\
\hline \multicolumn{2}{|l|}{ FIGO stage at initial diagnosis, n (\%) } \\
\hline I & $9(60)$ \\
\hline II & $1(6.6)$ \\
\hline III & $5(33.4)$ \\
\hline \multicolumn{2}{|l|}{ Histology, n (\%) } \\
\hline Endometrioid & $11(73.3)$ \\
\hline Serous & $2(13.3)$ \\
\hline Endometrial stromal sarcoma & $1(6.6)$ \\
\hline Leiomyosarcoma & $1(6.6)$ \\
\hline \multicolumn{2}{|l|}{ Grading } \\
\hline G1 & - \\
\hline G2 & $8(53.3)$ \\
\hline G3 & $7(46.7)$ \\
\hline LVSI, n $(\%)$ & $9(60)$ \\
\hline \multicolumn{2}{|l|}{ Previous treatment } \\
\hline Surgery & $7(46.6)$ \\
\hline Surgery plus CT & $2(13.3)$ \\
\hline Surgery plus RT & $4(26.6)$ \\
\hline Surgery plus combined CTRT & $1(6.6)$ \\
\hline RT plus CT only & $1(6.6)$ \\
\hline \multicolumn{2}{|l|}{ Sites of recurrence, $\mathrm{n}(\%)$} \\
\hline Single site & $5(33.3)$ \\
\hline Multifocal & $10(66.7)$ \\
\hline \multicolumn{2}{|l|}{ Sites of recurrence, n (\%) } \\
\hline Vagina & $13(86.7)$ \\
\hline Pelvis & $10(66.7)$ \\
\hline Bladder & $9(60)$ \\
\hline Rectum & $9(60)$ \\
\hline Peritoneum & $5(33.4)$ \\
\hline Pelvic nodes & $2(13.3)$ \\
\hline Para-aortic nodes & $2(13.3)$ \\
\hline Small bowel & $2(13.3)$ \\
\hline
\end{tabular}

CT indicates chemotherapy; RT, radiotherapy. 
TABLE 2. Perioperative and operative outcomes

\begin{tabular}{lc}
\hline Variables & Total \\
\hline Operation time, median (range), min & $225(21-370)$ \\
Estimated blood loss, median (range), mL & $200(10-500)$ \\
Complete tumor resection achieved, n (\%) & $15(100)$ \\
Procedures performed, n (\%) & \\
Pelvic peritoneal stripping & $9(60)$ \\
Partial or total colpectomy & $13(86.7)$ \\
Pelvic LND & $2(13.3)$ \\
Para-aortic LND & $2(13.3)$ \\
Bladder resection & \\
$\quad$ Partial & $5(33.4)$ \\
$\quad$ Complete (anterior exenteration) & $3(20)$ \\
Rectal resection & $3(20)$ \\
Ureteric resection and & $4(26.6)$ \\
$\quad$ ureteroneocystostomy & \\
Stoma formation (ileostomy/colostomy) & $3(20)$ \\
Ileal conduit & $3(20)$ \\
Large bowel resection & $3(20)$ \\
Small bowel resection & $4(26.6)$ \\
Primary bowel anastomosis & \\
Large bowel & $3(20)$ \\
Small bowel & $4(26.6)$ \\
\hline
\end{tabular}

Specific indications were the presence of multifocal peritoneal relapse (chemotherapy), extensive LVSI in bulky localized disease, and positive LN status.

\section{Statistics}

Interval data were analyzed using the Mann-Whitney $U$ test. Nominal data were evaluated using the $\chi^{2}$ test or Fisher exact test when appropriate. Disease-free interval was calculated from the end of previous treatment to the time of surgery at relapse. Progression-free survival (PFS) and overall survival (OS) were calculated from the date of relapse surgery to clinical diagnosis of progression and death, respectively. Survival was estimated using Kaplan-Meier methods. Parameters are expressed as median and range when achievable or, alternatively, as mean \pm SD and $95 \%$ confidence interval (CI). All statistical tests were performed using SPSS statistical software program (SPSS 20.0 Inc, Chicago, Ill).

\section{RESULTS}

A total of 15 patients were identified within the 3-year period from May 2013 to April 2016. The patients' median age at relapse surgery was 66 years (range, $33-83$ years). The median body mass index was $27.7 \mathrm{~kg} / \mathrm{m}^{2}$ (range, 24.8-37.5 $\mathrm{kg} / \mathrm{m}^{2}$ ). The International Federation of Gynecology and Obstetrics (FIGO) stage at initial diagnosis was I, II, and III in $60 \%, 6.6 \%$, and $33.4 \%$ of the patients, as per the new FIGO classification, respectively. ${ }^{9}$ A total of 11 patients $(73.3 \%)$ had endometrioid histology; 2 patients $(13.3 \%)$ had serous histology; and 2 patients (13.3\%) had uterine sarcoma, 1 with stromal sarcoma and the other with leiomyosarcoma.

Treatment at initial diagnosis was by abdominal $(n=12)$ or laparoscopic $(n=2)$ hysterectomy plus bilateral salpingooophorectomy. Pelvic and para-aortic lymphadenectomy was performed in only 1 of those patients. Just 1 patient received concomitant chemoradiation instead of surgery because of advanced stage of disease (stage III). Patient-related and tumorrelated characteristics are presented in Table 1. A total of 7 patients $(46.7 \%)$ had received postoperative adjuvant treatment with radiotherapy and/or chemotherapy with carboplatin and paclitaxel at initial diagnosis. As adjuvant radiation treatment, 4 patients $(26.6 \%)$ had undergone vaginal vault brachytherapy, whereas just 1 patient $(6.6 \%)$ had undergone whole pelvic irradiation.

Recurrent disease was symptomatic in only 3 patients $(26.6 \%)$ with vaginal bleeding $(n=2)$ or abdominal pain $(n=1)$. The rest of the patients were diagnosed at examination on follow-up.

Median disease-free interval between surgery at relapse and the end of previous treatment was 24 months (range, $8-164)$. A total of 5 patients $(33.3 \%)$ recurred at a single site, whereas the remaining patients $(66.7 \%)$ recurred multifocally within the abdominal and retroperitoneal cavity. Of the 5 patients with single site relapse, 2 patients $(13.3 \%)$ had isolated para-aortic lymph nodal recurrences, and $3(20 \%)$ had an isolated vaginal recurrence that could be completely resected with a wide local vaginal excision. Four of 5 patients who recurred at a single site had endometrioid histology, whereas the 1 patient with the para-aortic LN single recurrence had a serous histology. The types of relapse are summarized in Table 1.

TABLE 3. Patterns of further relapses after surgery for UC relapse

\begin{tabular}{lc}
\hline Variables & Total \\
\hline $\begin{array}{l}\text { Mean disease-free interval ever since } \\
\text { secondary surgery, mean (SD) }\end{array}$ & $12.4(10.5)$ \\
No. patients experiencing II relapse, n (\%) & $5(33.3)$ \\
Type of relapse, n (\%) & \\
$\quad$ None & $10(66.7)$ \\
$\quad$ Locoregional & $3(20)$ \\
$\quad$ Distant & $2(13.3)$ \\
Site of relapse, n (\%) & \\
Diffuse peritoneal carcinomatosis disease & $2(40)$ \\
$\quad$ Central pelvis/vaginal vault & $3(60)$ \\
Lateral pelvic sidewall & $1(20)$ \\
Pelvic lymph nodes & $1(20)$ \\
Lungs & $1(20)$ \\
Liver & $2(40)$ \\
Multiple recurrences, $\mathrm{n}(\%)$ & $2(40)$ \\
Treatment of II relapses, $\mathrm{n}(\%)$ & \\
Chemotherapy & $4(80)$ \\
Palliative care & $1(20)$ \\
\hline
\end{tabular}



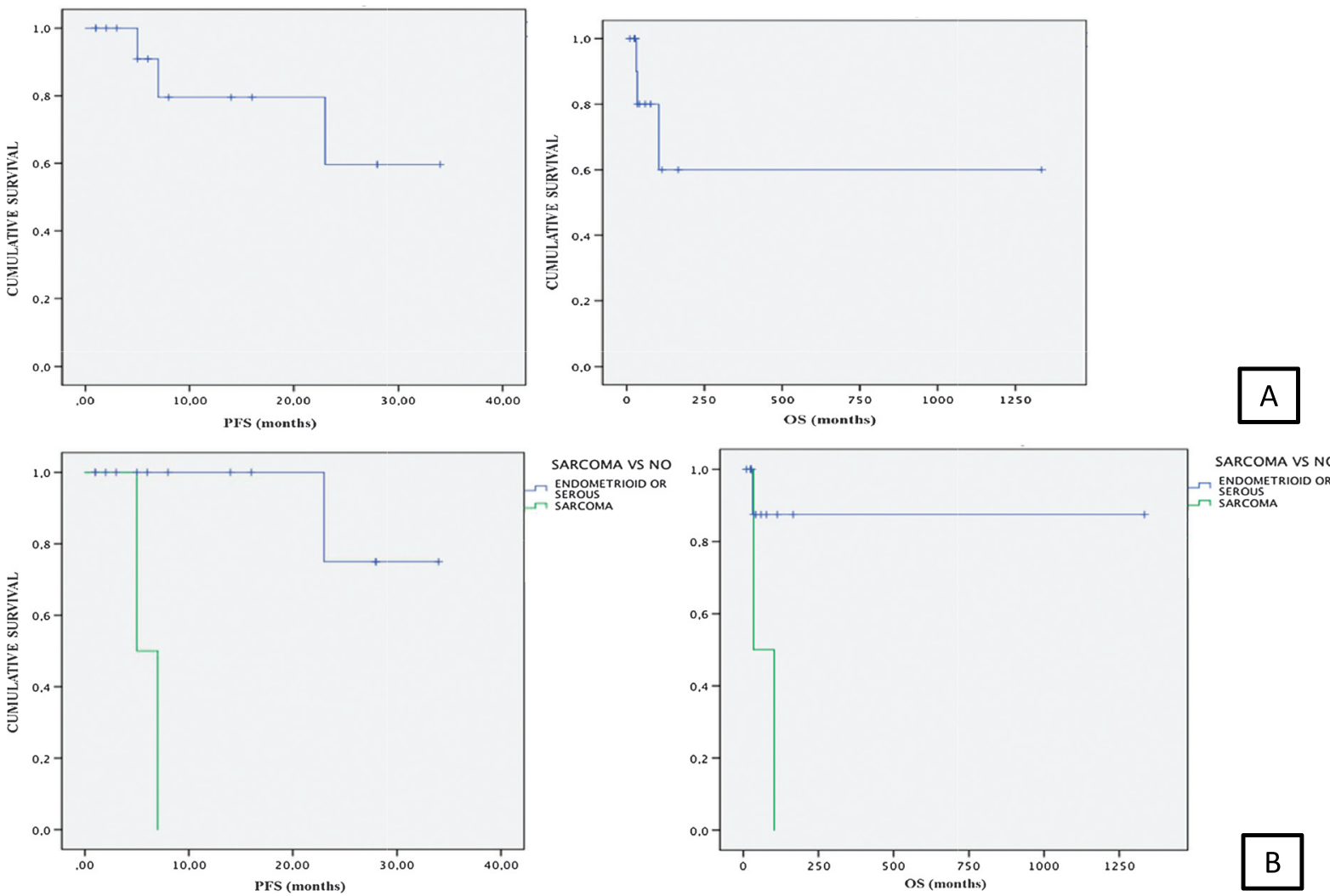

FIGURE 1. A, The PFS and OS after surgery for US relapse $(n=15) . B$, The PFS and OS in sarcomas and nonsarcomatous histotypes.

Complete tumor resection was achieved in all 15 patients $(100 \%)$. Three patients $(20 \%)$ underwent a total exenteration; all 3 of them had undergone previous whole pelvic irradiation. Details of the types of resections are presented in Table 2. Seven patients $(46.6 \%)$ underwent a bowel resection, and 8 patients $(53.3 \%)$ underwent a ureteric and/or bladder resection. All patients, apart from the 3 who underwent exenterations, received a primary bowel and/or ureteric anastomosis, without stoma formation.
Median operative time was 225 minutes (range, 21-370 minutes), and median blood loss was $300 \mathrm{~mL}$ (range, $100-600 \mathrm{~mL})$. Eight patients $(53.3 \%)$ underwent a perioperative blood transfusion. Median postoperative hospitalization was 5 days (range, 2-30 days). Major postoperative complications according to Clavien-Dindo classification system $^{10}$ were observed in only 1 patient $(6.7 \%)$ who developed a ureteric fistula in the ileal conduit anastomosis after exenteration. This was managed conservatively with

TABLE 4. Cytoreductive surgery in recurrent uterine cancers: literature review

\begin{tabular}{lcccc}
\hline Author & Type of Study & No. Patients & $\begin{array}{c}\text { Definition of Optimal } \\
\text { Cytoreduction }\end{array}$ & Optimal Cytoreduction, n (\%) \\
\hline Scarabelli et al, 1998 ${ }^{18}$ & Prospective & 20 & No grossly visible & $13(65)$ \\
Campagnutta et al, 2004 ${ }^{19}$ & Prospective & 75 & $\leq 1 \mathrm{~cm}$ & $56(74.5)$ \\
Awtrey et al, 2006 & Retrospective & 27 & $\leq 2 \mathrm{~cm}$ & $15(55.5)$ \\
Bristow et al, 2006 & Retrospective & 35 & No grossly visible & $23(65.7)$ \\
Ren et al, 2014 & Retrospective & 75 & $\leq 1 \mathrm{~cm}$ & $43(57.3)$ \\
Turan et al, 2015 & Retrospective & 34 & No grossly visible & $24(70.5)$ \\
Papadia et al, $2015^{8}$ & Retrospective & 64 & No grossly visible & $42(65.6)$ \\
\hline
\end{tabular}

*Nonoptimally versus optimally cyotreduced.

$\uparrow$ Nonsurgically treated versus surgically.

Estimated 5-year values in nonoptimally versus optimally cytoreduced; median values not available.

NS, not specified. 
TABLE 5. Multivisceral surgical procedures performed: comparison between studies in the literature

\begin{tabular}{|c|c|c|c|c|c|c|}
\hline \multirow[b]{3}{*}{ Author } & \multirow[b]{3}{*}{$\begin{array}{c}\text { Total } \\
\text { Patients }\end{array}$} & \multicolumn{5}{|c|}{ Type of Resection, N (\%) } \\
\hline & & \multicolumn{2}{|c|}{ Bowel Resection } & \multicolumn{2}{|c|}{ Bladder Resection } & \multirow[b]{2}{*}{$\begin{array}{l}\text { Exenterative Procedure } \\
\text { (Anterior or Posterior) }\end{array}$} \\
\hline & & $\begin{array}{l}\text { Small Bowel, } \\
\text { n (\%) }\end{array}$ & $\begin{array}{l}\text { Large Bowel, } \\
\text { n (\%) }\end{array}$ & Partial & Complete & \\
\hline Scarabelli et al, $1998^{18}$ & 20 & $6(30)$ & $5(25)$ & 0 & 0 & $3(15)$ \\
\hline Campagnutta et al, $2004^{19}$ & 75 & $9(12)$ & $8(11)$ & 0 & 0 & $13(17.5)$ \\
\hline Awtrey et al, $2006^{20}$ & 27 & $3(11)$ & $4(15)$ & 0 & 0 & 0 \\
\hline Bristow et al, $2006^{21}$ & 35 & $5(14.3)$ & $7(20)$ & $1(2.9)$ & 0 & 0 \\
\hline Ren et al, $2014^{22}$ & 75 & $6(8)$ & $19(25)$ & $2(2.7)$ & 0 & 0 \\
\hline Turan et al, $2015^{23}$ & 34 & $3(8.8)$ & $4(11.8)$ & 0 & 0 & - \\
\hline Papadia et al, $2015^{8}$ & 64 & \multicolumn{2}{|c|}{$6(9)^{*}$} & \multicolumn{2}{|c|}{$7(11)^{*}$} & $5(8)$ \\
\hline
\end{tabular}

bilateral nephrostomies for 3.5 weeks. There were no postoperative deaths within 30 days.

Five patients $(33.3 \%)$ received adjuvant treatment after relapse cytoreductive surgery. Four patients $(26.7 \%)$ received platinum-based systemic chemotherapy, and 1 patient $(6.7 \%)$ had pelvic radiotherapy as per MDT recommendation. The others did not receive any adjuvant treatment either because they had undergone an exenteration that is why no evidence exists for adjuvant treatment postexenteration, or they had a completely excised, single-site recurrence (vaginal or paraaortic area).

After surgery for recurrence, 5 patients (33.3\%) had experienced a further recurrence after a median interval of 7 months during a mean follow-up period of $12.4 \pm 10.5$ months (95\% CI, 6.5-18.2). Two of those patients had a sarcomatous component, and they were anticipated to relapse rather soon, as 1 patient was undergoing her fifth surgery for peritoneally disseminated low-grade stromal sarcoma with initial diagnosis 12 years before, and the other patient had leiomyosarcoma relapse with severe pelvic symptoms and had failed all previous systemic and radiotherapeutic options.
Second relapse sites were locoregional in 3 patients (diffuse pelvic disease and pelvic lymph nodes) and distant in 2 of them (diffuse abdominal carcinomatosis in 1 patient and pulmonary in the other). Interestingly, all patients who relapsed again locally had undergone previous radiotherapy so they could not have any further radiotherapy. Treatment after further relapse included palliative chemotherapy in 4 patients, whereas 1 patient received best supportive care because of large disease burden. Three of the 5 patients who relapsed died. Detailed data regarding second relapses are shown in Table 3.

The mean PFS was $21.7 \pm 4.0$ months $(95 \% \mathrm{CI}$, 13.9-29.5), and the mean OS was $26.0 \pm 3.9$ months $(95 \% \mathrm{CI}$, 18.4-29.5) as shown in Figure 1A. Median PFS was 16 months, whereas median OS was not reached yet. If we analyze separately the nonsarcoma and the sarcoma patients, then mean PFS is $25.4 \pm 3.9$ months versus only $6.0 \pm 1.0$ months, respectively $(P<0.0001)$, and mean OS is $31.1 \pm 2.7$ months versus $8.5 \pm 0.5$ months, respectively $(P<0.0001)$ (Fig. 1B).

Additional analysis and stratification according to the presence of LVSI, advanced age older than 70 years, and sites

\begin{tabular}{cccccc}
\hline $\begin{array}{c}\text { Postoperative } \\
\text { Deaths, n (\%) }\end{array}$ & $\begin{array}{c}\text { Major } \\
\text { Complication Rate, \% }\end{array}$ & $\begin{array}{c}\text { Median Follow-up After } \\
\text { Recurrence, mo }\end{array}$ & $\begin{array}{c}\text { Median } \\
\text { PFS, mo }\end{array}$ & $\begin{array}{c}\text { Median OS After } \\
\text { Recurrence, mo }\end{array}$ & $\begin{array}{c}\text { Subsequent } \\
\text { Relapses, n (\%) }\end{array}$ \\
\hline $2(10)$ & 15 & 15 & 8.1 & 11.8 & $6(46)$ \\
$6(8)$ & 30.7 & 14 & 13 & $19\left(9-53^{*}\right)$ & $43(64.2)$ \\
0 & 48 & 24 & 14 & $35\left(10-43^{*}\right)$ & NS \\
0 & 31.4 & 22 & 18 & $24(13-28 \dagger)$ & NS \\
0 & 12 & NS & 9 & 18 & NS \\
0 & 27.3 & 13.5 & 16.5 & $40\left(9-53^{*}\right)$ & NS \\
0 & $17.2 \%$ & NS & $19-42 \ddagger$ & $30-60 \%$ & NS \\
\hline
\end{tabular}


TABLE 6. Patient-related and disease-related characteristics of women who underwent surgery for UC relapse

\begin{tabular}{|c|c|c|c|c|c|}
\hline $\begin{array}{l}\text { Patients' } \\
\text { No. ID }\end{array}$ & $\begin{array}{l}\text { Age at } \\
\text { the Time } \\
\text { of Surgery }\end{array}$ & $\begin{array}{l}\text { Histological } \\
\text { Subtype }\end{array}$ & $\begin{array}{c}\text { Initial } \\
\text { Treatment (Surgery } \\
\text { and Adjuvant) }\end{array}$ & $\begin{array}{l}\text { Time Between } \\
\text { Initial Diagnosis } \\
\text { and Surgery for } \\
\text { Relapse, mo }\end{array}$ & Sites of Relapse \\
\hline No. 1 & 71 & Endometrioid & Surgery plus adjuvant BCT & 99 & Multifocal in pelvis \\
\hline No. 2 & 71 & Endometrioid & Surgery & 30 & Vaginal introitus \\
\hline No. 3 & 66 & Endometrioid & Surgery & 84 & Vaginal introitus \\
\hline No. 4 & 64 & Endometrioid & Surgery plus adjuvant RT & 71 & Multifocal in pelvis \\
\hline No. 5 & 33 & Endometrioid & Surgery & 8 & Multifocal in pelvis \\
\hline No. 6 & 83 & Serous & Surgery plus adjuvant BCT & 16 & Multifocal in pelvis \\
\hline No. 7 & 77 & Endometrioid & Surgery plus adjuvant CT & 18 & Para-aortic lymphadenopathy \\
\hline No. 8 & 58 & Endometrioid & Surgery & 18 & Multifocal in pelvis \\
\hline No. 9 & 70 & Endometrioid & Surgery & 164 & $\begin{array}{l}\text { Multifocal pelvis } \\
\text { and pelvic } \\
\text { lymphadenopathy }\end{array}$ \\
\hline No. 10 & 76 & Serous & Surgery plus adjuvant RTCT & 17 & Para-aortic lymphadenopathy \\
\hline No. 11 & 66 & Endometrioid & Surgery plus adjuvant BCT & 23 & $\begin{array}{l}\text { Multifocal in pelvis } \\
\text { and pelvic } \\
\text { lymphadenopathy }\end{array}$ \\
\hline No. 12 & 61 & Endometrioid & Surgery & 8 & Vaginal introitus \\
\hline No. 13 & 42 & Endometrioid & Surgery plus adjuvant CT & 24 & Multifocal in pelvis \\
\hline No. 14 & 50 & $\begin{array}{l}\text { Endometrial } \\
\text { stromal sarcoma }\end{array}$ & Surgery & 93 & $\begin{array}{l}\text { Multifocal peritoneal } \\
\text { dissemination }\end{array}$ \\
\hline No. 15 & 49 & $\begin{array}{l}\text { Endometrial } \\
\text { stromal sarcoma }\end{array}$ & CTRT & 26 & $\begin{array}{l}\text { Multifocal in pelvis, } \\
\text { small, and large bowel }\end{array}$ \\
\hline
\end{tabular}

BCT, brachytherapy; DOD, dead of disease; NED, no evidence of disease; PD, progression of disease.

of relapse (pelvic vs extrapelvic) have been performed but differences in survival were not statistically significant.

\section{DISCUSSION}

Endometrial cancer is usually diagnosed early $(80 \%$ FIGO stage I), with excellent 5-year survival rates reaching $95 \%{ }^{11}$ The overall rate of recurrence across all stages and histological subtypes is about $10 \%$ to $15 \%$ in the first 3 years after primary diagnosis. ${ }^{12,13}$ Nevertheless, 5-year survival rates are worse if there is locoregional spread $(68 \%)$ or distant spread $(17 \%)^{12-15}$

Treatment options for recurrent disseminated UC are rather limited and prognosis can be poor depending on the patterns of relapse. Management options depend on type of relapse (unifocal vs multifocal), sites of relapse, and previous treatment modalities. Radiotherapy still represents the mainstay in radiotherapy-naive local recurrence cases, with chemotherapy being preferable in systemic recurrences.

With surgical advances and techniques improving over the recent years, improved survival seems to have been associated also with more radical techniques such as pelvic exenteration and lateral extended pelvic sidewall resection in patients with central or lateral pelvic wall recurrences. Debulking surgery is therefore developing as alternative treatment option in the recurrent setting, ${ }^{16,17}$ a concept recently reiterated by the "ESMO-ESGO-ESTRO Consensus Conference on Endometrial Cancer" in 2016. ${ }^{15}$

However, experience of debulking surgery feasibility in the recurrent setting is limited, and morbidity is currently not 


\begin{tabular}{|c|c|c|c|c|}
\hline $\begin{array}{l}\text { Surgical Procedures } \\
\text { Performed }\end{array}$ & $\begin{array}{c}\text { Time of } \\
\text { Follow-up, mo }\end{array}$ & $\begin{array}{l}\text { Postoperative } \\
\text { Complications }\end{array}$ & $\begin{array}{l}\text { Second Relapse Sites } \\
\text { and Time of Relapse }\end{array}$ & $\begin{array}{l}\text { Status at Last } \\
\text { Follow-up }\end{array}$ \\
\hline $\begin{array}{l}\text { Partial colpectomy, anterior rectal } \\
\text { resection with end to end anastomosis, } \\
\text { and partial bladder resection }\end{array}$ & 34 & None & None & NED \\
\hline Local vaginal excision & 28 & None & None & NED \\
\hline Local vaginal excision & 28 & None & None & NED \\
\hline Total exenteration & 5 & None & $\begin{array}{l}\text { Massive } \\
\text { intra-abdominal }\end{array}$ & DOD \\
\hline $\begin{array}{l}\text { Partial colpectomy, bladder partial } \\
\text { resection, and pelvic } \\
\text { peritoneal stripping }\end{array}$ & 23 & None & None & NED \\
\hline $\begin{array}{l}\text { Partial colpectomy, bladder partial } \\
\text { resection, and pelvic } \\
\text { peritoneal stripping }\end{array}$ & 16 & None & Pelvic & PD \\
\hline Para-aortic LND & 6 & None & None & NED \\
\hline Total exenteration & 14 & None & Pelvic & PD \\
\hline $\begin{array}{l}\text { Partial colpectomy, anterior rectal } \\
\text { resection with end to end anastomosis, } \\
\text { and peritoneal stripping, pelvic LND }\end{array}$ & 1 & None & None & NED \\
\hline Para-aortic LND & 8 & None & None & NED \\
\hline $\begin{array}{l}\text { Partial colpectomy, bladder partial } \\
\text { resection, pelvic LND, and } \\
\text { peritoneal stripping }\end{array}$ & 6 & None & None & NED \\
\hline Local vaginal excision & 4 & None & None & NED \\
\hline $\begin{array}{l}\text { Partial colpectomy, bladder partial } \\
\text { resection, anterior rectal resection with } \\
\text { end to end anastomosis, and pelvic } \\
\text { peritoneal stripping }\end{array}$ & 1 & None & None & NED \\
\hline $\begin{array}{l}\text { Peritoneal stripping pelvis, paracolic, } \\
\text { small bowel resection, and anastomosis }\end{array}$ & 5 & None & $\begin{array}{l}\text { Massive abdominal } \\
\text { and lungs }\end{array}$ & DOD \\
\hline Total exenteration & 7 & $\begin{array}{l}\text { Ureteric fistula in the ileal } \\
\text { conduit anastomosis }\end{array}$ & Pelvis and nodes & DOD \\
\hline
\end{tabular}

well described. Patients with endometrial cancer are frequently elderly, overweight, and affected by numerous comorbidities, thus surgery has to be carefully planned and tailored within a multidisciplinary setting. Additional factors such as previous pelvic irradiation make any future surgery even more challenging because of the loss of anatomical planes, the tissue reaction, and impaired tissue healing, necessitating specialized expertise.

Scarabelli et $\mathrm{al}^{18}$ were the first to report in 1998 their experience in a series of 20 women with recurrent endometrial cancer, achieving an optimal debulking (no detectable disease) in $65 \%$ of cases. Complications occurred in $15 \%$ of patients with $46 \%$ of the patients experiencing further recurrence. Median survival time after recurrence was 11.8 months, and the mortality rate was $10 \%$.

Campagnutta and colleagues ${ }^{19}$ published data on a series of 75 patients who underwent surgery for relapsed UC. Complete tumor resection (indicated as residual disease
$<1 \mathrm{~cm}$ ) was achieved in $74.5 \%$ of patients, with a complication rate of $30.7 \%(n=41)$. Median survival after recurrence was 19 months with a significant difference between patients undergoing suboptimal and optimal cytoreduction $(P<0.05)$. In this series, a postoperative mortality of $8 \%$ was observed.

In 2006 , Awtrey et $\mathrm{al}^{20}$ reported a series of 27 surgical procedures in patients with recurrent endometrial cancer. Residual tumor that is less than or equal to $2 \mathrm{~cm}$ (indicated in the paper as optimal cytoreduction following Gynecologic Oncology Group $122^{20}$ criteria) was obtained in $56 \%$ of patients. Also in this article, median postrecurrence survival time was considerably longer in patients with "optimal" compared with nonoptimal residual disease, even though $2 \mathrm{~cm}$ residual tumor would not nowadays be considered as optimal (43 vs 10 months; $P<0.01$ )

In the US, Bristow et $\mathrm{al}^{21}$ evaluated the outcomes of 35 patients with relapse who underwent surgery compared with 
patients not treated surgically. Optimal cytoreduction (no macroscopic residual disease) was attained in $66 \%$ of cases. Complications were observed in $31.4 \%$ of cases. Median survival time after relapse was 24 months, and it was significantly longer in patients after surgical treatment than in patients treated nonsurgically (28 vs 13 months; $P<0.0001$ ). Again, residual disease was recognized as a predictor of survival.

Similar results were reported by a Chinese group, evaluating 75 Chinese patients with recurrent endometrial cancer and obtaining "optimal cytoreduction" (residual disease $\leq 1 \mathrm{~cm}$ ) in $57.3 \%$ of the patients. ${ }^{22}$ The complication rate was $12 \%$, and the median survival was 18 months.

More recently, Papadia and colleagues ${ }^{8}$ described the outcomes obtained with secondary cytoreductive surgery in 64 recurrent endometrial cancer patients, achieving optimal debulking in $65.6 \%$ of them. The complication rate was $17.2 \%$. The median survival time was considerably worse in suboptimally cytoreduced patients, also in this series (estimated 5-year OS, $30 \%$ vs $60 \% ; P=0.01$ ).

In our series, complete resection, interpreted as no visible residual tumor, was obtained in all cases most probably because of careful patient selection. Despite the complex multivisceral resection techniques, major morbidity was low at $6 \%$, which again may be attributed to a favorable patient cohort with good performance status and no serious comorbidities. Survival after recurrence was satisfactory compared with other studies ${ }^{8,18-23}$ with patients with true sarcomatous histology exhibiting poorer overall outcome. Comparisons between the studies are summarized in Tables 4 and 5. Specific data about patients who underwent surgery for UC relapse are shown in Table 6.

Achieving complete debulking is fundamental to conferring a survival benefit, ${ }^{24,25}$ similar to our experience of surgery for ovarian cancer. ${ }^{24-27}$ Meticulous planning and consideration of both patient-related and tumor-related factors are key to achieve a good surgical outcome.

The main limitations of this study are the small sample size from a single United Kingdom center and the lack of short and long term quality of life data. Considering that the surgical treatment of relapsed endometrial cancer is nonstandard in the United Kingdom, our aim was to demonstrate feasibility of this approach in a United Kingdom/National Health Service environment with narrow breaching times, limited theater space, and intensive care availability and therefore a mainly nonsurgical approach of treatment of gynecological cancer relapse. ${ }^{28}$

We could show that complex surgical procedures for relapsed endometrial cancer can be performed safely in such an environment, adding further evidence to the encouraging experience of surgery in this setting. Nevertheless, larger scale multicenter international analyses or even better prospective randomized clinical trials are warranted to establish the value and survival benefit of surgery in recurrent endometrial cancer, because small, single-center analyses alone are definitely not enough to validate and establish such an approach.

Key factors would be how to identify the ideal surgical candidate to enable a more individualized surgical approach, and to evaluate quality of life outcomes. Multidisciplinary and infrastructural support, effort, and expertise seem vital to prevent unnecessary morbidity, whereas quality of life outcomes require further evaluation.

\section{REFERENCES}

1. American Cancer Society. Cancer Facts and Figures 2013. Atlanta, GA: American Cancer Society; 2013.

2. Barlin JN, Wysham WZ, Ferda AM, et al. Location of disease in patients who die from endometrial cancer: a study of 414 patients from a single institution. Int J Gynecol Cancer. 2012;22:1527-1531.

3. Creutzberg CL, van Stiphout RG, Nout RA, et al. Nomograms for prediction of outcome with or without adjuvant radiation therapy for patients with endometrial cancer: a pooled analysis of PORTEC-1 and PORTEC-2 trials. Int J Radiat Oncol Biol Phys. 2015;91:530-539.

4. SGO Clinical Practice Endometrial Cancer Working Group, Burke WM, Orr J, et al. Endometrial cancer: a review and current management strategies: part II. Gynecol Oncol. 2014;134:393-402.

5. Creasman WT, Odicino F, Maisonneuve P, et al. Carcinoma of the corpus uteri. FIGO 26th annual report on the results of treatment in gynecological cancer. Int J Gynaecol Obstet. 2006;95(suppl 1):S105-S143.

6. Randall ME, Filiaci VL, Muss H, et al. Randomized phase III trial of whole-abdominal irradiation versus doxorubicin and cisplatin chemotherapy in advanced endometrial carcinoma: a Gynecologic Oncology Group Study. J Clin Oncol. 2006;24:36-44.

7. Nagao S, Nishio S, Michimae H, et al. Applicability of the concept of "platinum sensitivity" to recurrent endometrial cancer: the SGSG-012/GOTIC-004/Intergroup study. Gynecol Oncol. 2013;131:567-573.

8. Papadia A, Bellati F, Ditto A, et al. Surgical treatment of recurrent endometrial cancer: time for a paradigm shift. Ann Surg Oncol. 2015;22:4204-4210.

9. Pecorelli S. Revised FIGO staging for carcinoma of the vulva, cervix, and endometrium. Int J Gynaecol Obstet. 2009;105:103-104. Erratum in: Int J Gynaecol Obstet. 2010;108:176.

10. Dindo D, Demartines N, Clavien PA. Classification of surgical complications: a new proposal with evaluation in a cohort of 6336 patients and results of a survey. Ann Surg. 2004;240:205-213.

11. National Cancer Institute. Endometrial cancer treatment Physician Data Query (PDQ). Available at: https://www.cancer. gov/types/uterine/hp/endometrial-treatment-pdq Accessed February 2, 2016.

12. Del Carmen MG, Boruta DM 2nd, Schorge JO. Recurrent endometrial cancer. Clin Obstet Gynecol. 2011;54:266-277.

13. Creutzberg CL, Nout RA, Lybeert ML, et al. Fifteen-year radiotherapy outcomes of the randomized PORTEC-1 trial for endometrial carcinoma. Int J Radiat Oncol Biol Phys. 2011;81:e631-e638.

14. Dowdy SC, Mariani A, Cliby WA, et al. Radical pelvic resection and intraoperative radiation therapy for recurrent endometrial cancer: technique and analysis of outcomes. Gynecol Oncol. 2006;101:280-286.

15. Colombo N, Creutzberg C, Amant F, et al. ESMO-ESGOESTRO Consensus Conference on Endometrial Cancer: diagnosis, treatment and follow-up. Int J Gynecol Cancer. 2016;26:2-30.

16. Bakrin N, Cotte E, Sayag-Beaujard A, et al. Cytoreductive surgery with hyperthermic intraperitoneal chemotherapy for the treatment of recurrent endometrial carcinoma confined to the peritoneal cavity. Int J Gynecol Cancer. 2010;20:809-814. 
17. Barlin JN, Puri I, Bristow RE. Cytoreductive surgery for advanced or recurrent endometrial cancer: a meta-analysis. Gynecol Oncol. 2010;118:14-18.

18. Scarabelli C, Campagnutta E, Giorda G, et al. Maximal cytoreductive surgery as a reasonable therapeutic alternative for recurrent endometrial carcinoma. Gynecol Oncol. 1998;70:90-93.

19. Campagnutta E, Giorda G, De Piero G, et al. Surgical treatment of recurrent endometrial carcinoma. Cancer. 2004;100:89-96.

20. Awtrey CS, Cadungog MG, Leitao MM, et al. Surgical resection of recurrent endometrial carcinoma. Gynecol Oncol. 2006;102:480-488.

21. Bristow RE, Santillan A, Zahurak ML, et al. Salvage cytoreductive surgery for recurrent endometrial cancer. Gynecol Oncol. 2006;103:281-287.

22. Ren Y, Shan B, Shi D, et al. Salvage cytoreductive surgery for patients with recurrent endometrial cancer: a retrospective study. BMC Cancer. 2014; 14:135.

23. Turan T, Tasci T, Karalok A, et al. Salvage cytoreductive surgery for recurrent endometrial cancer. Int J Gynecol Cancer. 2015;25:1623-1632.
24. Maggioni A, Roviglione G, Landoni F, et al. Pelvic exenteration: ten-year experience at the European Institute of Oncology in Milan. Gynecol Oncol. 2009;114:64-68.

25. Bristow RE, Peiretti M, Gerardi M, et al. Secondary cytoreductive surgery including rectosigmoid colectomy for recurrent ovarian cancer: operative technique and clinical outcome. Gynecol Oncol. 2009;114:173-177.

26. Zang RY, Harter P, Chi DS, et al. Predictors of survival in patients with recurrent ovarian cancer undergoing secondary cytoreductive surgery based on the pooled analysis of an international collaborative cohort. Br J Cancer. 2011;105:890-896.

27. Sharma S, Odunsi K, Driscoll D, et al. Pelvic exenterations for gynecological malignancies: twenty-year experience at Roswell Park Cancer Institute. Int J Gynecol Cancer. 2005;15:475-482.

28. Barton DP, Adib T, Butler J. Surgical practice of UK gynaecological oncologists in the treatment of primary advanced epithelial ovarian cancer (PAEOC): a questionnaire survey. Gynecol Oncol. 2013;131:347-351. 